\title{
Maximum Preservation of the Media in Carotid Endarterectomy
}

\author{
Kuniyasu NiIZUMA, ${ }^{1}$ Hiroaki SHIMIZU, ${ }^{1,+}$ Takashi InOUE, ${ }^{2}$ Mika WATANABE, ${ }^{3}$ \\ and Teiji TOMINAGA ${ }^{1}$ \\ Departments of ${ }^{1}$ Neurosurgery and ${ }^{3}$ Pathology, Tohoku University Graduate School of \\ Medicine, Sendai, Miyagi; \\ ${ }^{2}$ Department of Neurosurgery, Sendai Medical Center, Sendai, Miyagi; \\ ${ }^{+}$Department of Neurosurgery, Akita University School of Medicine, \\ Akita, Akita (current affiliation)
}

\begin{abstract}
Carotid endarterectomy (CEA) is intended to remove atheromatous plaque by dissecting a plane between the intima and the media (circular medial fibers), but this may not be the optimal dissection plane. The present technique is based on identifying the plane that divides the media from the plaque, so preserving the media on the adventitia as much as possible. This plane is more difficult to find and follow than the easy-to-dissect plane usually located between the media and the adventitia, because the plaque invades the media and so the dividing plane is located within the media. In this prospective observational study, CEA was performed in 22 patients to histologically examine the excised plaques and small samples of the whole arterial wall, and evaluate the clinical outcomes. Plaque had invaded the luminal part of the media in the whole arterial wall sample of $80 \%$ of cases. Thin medial layers covering $>80 \%$ of the surface of the plaque were found in 16 of 22 plaques $(73 \%)$. Some atheromatous component was sometimes left in the preserved media, rather than completely removed with the media. No morbidity or mortality had occurred by discharge. Only 1 small ipsilateral infarction $(4.5 \%)$ and no restenosis of greater than $50 \%$ were detected during the mean follow-up period of 7 years. Since the plaque usually invades the media, the optimum dissection plane may be located within the media, dividing it into two layers. The presence of some remnant atheromatous components in the preserved media was not associated with surgical complications or restenosis.
\end{abstract}

Key words: carotid endarterectomy, dissection, media, plaque

\section{Introduction}

Carotid endarterectomy (CEA) is an established treatment indicated for specific patients with severe carotid stenosis who fulfill certain criteria. ${ }^{1)}$ Recent comparative studies of CEA with carotid artery stenting may determine the correct indications for each treatment. ${ }^{2-4)}$ Continued refinement of surgical techniques for CEA is essential to achieve the highest possible level of safety.

The wall of the carotid artery in the neck consists of, from the luminal side, the intima, the internal elastic lamina, the media, the external elastic lamina, and the adventitia. The media is formed of smooth muscle cells in a circumferential arrangement around the lumen, so these cells constitute what is called the circular medial fibers. ${ }^{5)}$ Atheromatous plaque

Received May 29, 2014; Accepted June 23, 2014 is thought to originate from accumulation of lipids in the intima, which is normally a thin layer. The internal elastic lamina is destroyed during the formation of plaque, and the border between the intima (plaque) and the media becomes obscure. Advanced plaque may cause atrophy of the media with loss of smooth muscle cells and elastic tissues. ${ }^{6,7)}$

Major surgical studies and text books recommend or imply that the dissection plane for CEA should be located between the thickened intima (plaque) and the media, which theoretically preserves the media as the luminal surface of the arterial wall and is reportedly the easiest plane to dissect. ${ }^{5,8-10)}$ However, one previous study identified media in all of the 147 CEA specimens, ${ }^{11)}$ and we also have experienced technical difficulty in dissecting between the plaque and the media. This technical issue is important not only for safe CEA but also for the training of young surgeons. 
We present a CEA technique to achieve maximum preservation of the media while removing the plaque, and the results of histological evaluation of the plaques and whole arterial wall samples. Clinical outcomes of the present technique were evaluated with long-term follow-up findings.

\section{Methods and Technical Presentation}

\section{Patient characteristics}

This prospective observational study included 22 consecutive male patients aged between 57 and 76 years (mean 69 years) treated between January and August, 2005. Seven patients were asymptomatic and 15 were symptomatic. Demographic and clinical data are presented in Table 1 . The patients treated with the present technique were evaluated in the short- and long term for possible adverse events including recurrent stenosis and/or infarction. The patients provided informed consent in writing.

\section{Surgical strategy}

Our surgical strategy remained unchanged during the study period. Surgical indications were based on the American Heart Association/American Stroke Association Stroke Council guidelines ${ }^{12)}$ and the Japanese guidelines. ${ }^{13)}$ Surgery employed general anesthesia and typical anterior cervical skin incision. Regional cerebral oxygen saturation $\left(\mathrm{rSO}_{2}\right)$ in the bilateral frontal cortices was monitored using INVOS $^{\mathrm{TM}}$ (Somanetics Inc., Troy, Michigan). Shortlatency somatosensory evoked potentials (SSEPs) were monitored throughout the surgery. Internal shunting was performed following clamping of the carotid artery if the $\mathrm{rSO}_{2}$ declined by around $10 \%$ or more of the preclamping value or if any changes occurred in the SSEPs.

\section{Surgical technique to preserve the media}

After the carotid artery was clamped, a shallow arterial incision was made with a scalpel to just reach the plaque under the operating microscope. At the beginning of dissection of the plaque, the adventitia was gently retracted and a blunt dissector was gently used to find the dissection plane (Fig. 1A-C). Following the easy-to-dissect plane

Table 1 Patient characteristics and histological findings

\begin{tabular}{|c|c|c|c|c|}
\hline \multirow{2}{*}{$\begin{array}{l}\text { Patient } \\
\text { No. }\end{array}$} & \multirow{2}{*}{$\begin{array}{l}\text { Age } \\
\text { (yrs) }\end{array}$} & \multirow{2}{*}{ Preoperative diagnosis } & \multicolumn{2}{|c|}{ Histological examination } \\
\hline & & & Media on plaque ${ }^{\# 1}$ & Whole wall sample ${ }^{\# 2}$ \\
\hline 1 & 60 & Asymptomatic & $30 \%$ & $\mathrm{NE}$ \\
\hline 2 & 74 & Asymptomatic & $80 \%$ & $\mathrm{NE}$ \\
\hline 3 & 74 & Asymptomatic & $80 \%$ & Plaque invasion to media \\
\hline 4 & 62 & Asymptomatic & $90 \%$ & $\mathrm{NE}$ \\
\hline 5 & 63 & Asymptomatic & $90 \%$ & Plaque within intima \\
\hline 6 & 70 & Asymptomatic & $90 \%$ & Plaque invasion to media \\
\hline 7 & 71 & Asymptomatic & $90 \%$ & Plaque invasion to media \\
\hline 8 & 70 & Ischemic ocular disease & $90 \%$ & Plaque invasion to media \\
\hline 9 & 64 & TIA & $50 \%$ & $\mathrm{NE}$ \\
\hline 10 & 73 & TIA & $80 \%$ & $\mathrm{NE}$ \\
\hline 11 & 65 & TIA & $80 \%$ & NE \\
\hline 12 & 71 & TIA & $90 \%$ & $\mathrm{NE}$ \\
\hline 13 & 76 & Minor completed stroke & $0 \%$ & $\mathrm{NE}$ \\
\hline 14 & 67 & Minor completed stroke & $30 \%$ & $\mathrm{NE}$ \\
\hline 15 & 74 & Minor completed stroke & $50 \%$ & $\mathrm{NE}$ \\
\hline 16 & 60 & Minor completed stroke & $70 \%$ & Unclear \\
\hline 17 & 64 & Minor completed stroke & $80 \%$ & Plaque invasion to media \\
\hline 18 & 57 & Minor completed stroke & $80 \%$ & Plaque invasion to media \\
\hline 19 & 77 & Minor completed stroke & $90 \%$ & $\mathrm{NE}$ \\
\hline 20 & 71 & Minor completed stroke & $90 \%$ & $\mathrm{NE}$ \\
\hline 21 & 75 & Minor completed stroke & $90 \%$ & Plaque invasion to media \\
\hline 22 & 74 & Minor completed stroke & $90 \%$ & Plaque invasion to adventitia \\
\hline
\end{tabular}

All patients were male. \#1: Percentage of the total circumference of the section (at the middle of the plaque) covered by the media. \#2: See text for detail. NE: not examined, TIA: transient ischemic attack. 

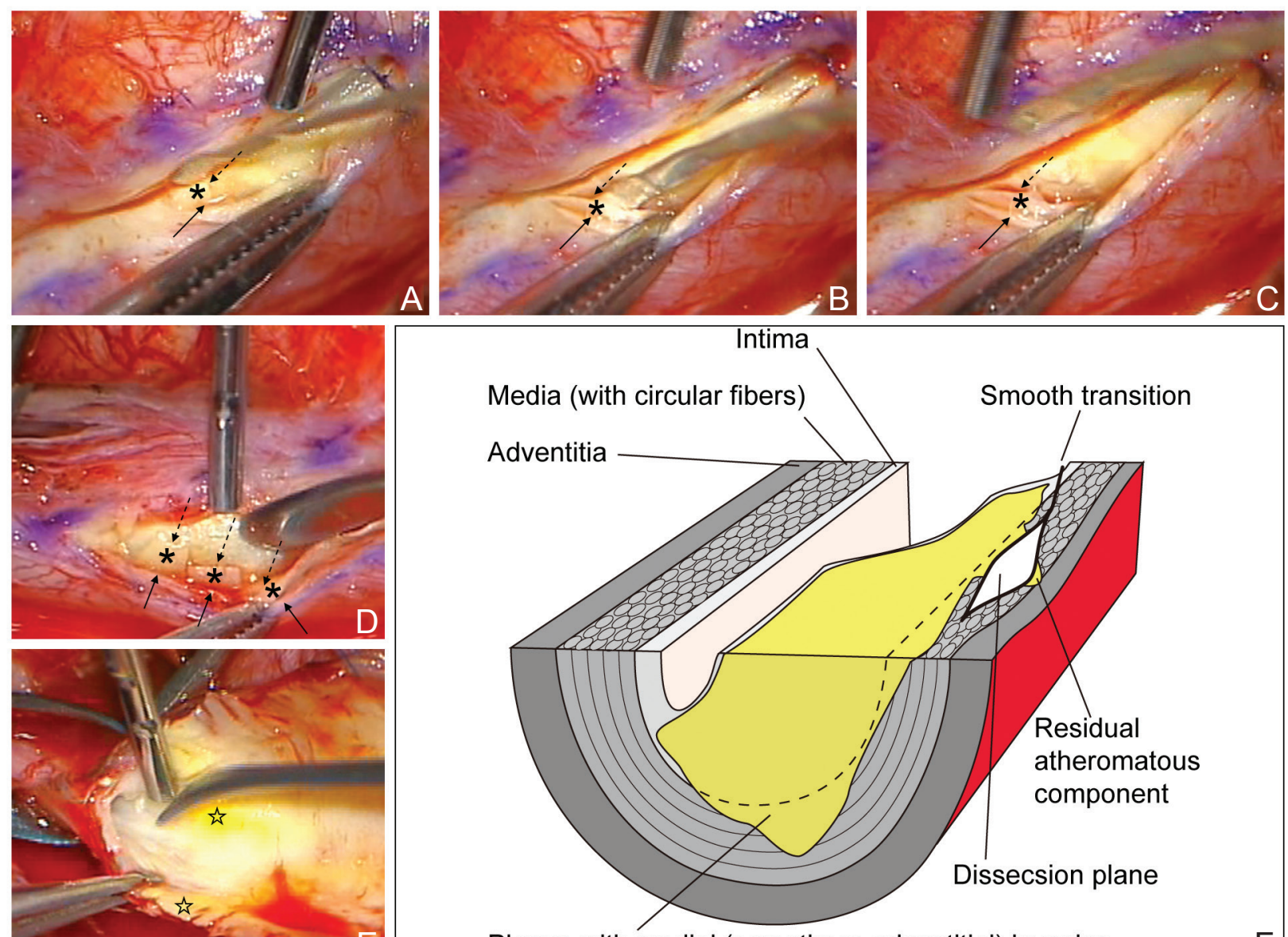

Plaque with medial (sometimes adventitial) invasion

Fig. 1 Intraoperative photographs showing the meticulous technique to preserve the media (A-E) and a schematic drawing of the present technique (F). A: After initial arterial incision with a scalpel, gentle retraction of the adventitia opened the easiest plane to dissect, just luminal to the adventitia (arrow). A layer of the media (asterisk) was detached from the arterial wall. To preserve the media on the arterial wall, a plane next luminal to the easiest plane should be dissected (dotted arrow). B, C: Using a blunt spatula, the plane to preserve the media (asterisks) was opened and followed (dotted arrows). D: During the effort to find a plane to leave the media attached to the arterial wall, the media sometimes formed a free flap (asterisks). This flap was removed for histological investigation (Fig. 3). E: After completion of plaque removal, smooth transition was formed to the intima of distal internal carotid artery, and yellowish atheromatous components remained with the media (stars). F: Dissection plane was located within the media, dividing it into two layers. The distal end of the endarterectomy smoothly transits to the intima of the internal carotid artery.

usually leaves almost no circular fibers (media) on the arterial wall but many on the plaque being removed, so the plane between the media and the adventitia was not followed further (Fig. 1A-C). Instead, a dissection plane that left the maximal amount of the media on the arterial wall was found and followed under high magnification (Fig. 1B, C). This plane was usually located just luminal to the easy-to-dissect plane and was also a tighter plane to dissect. Since the media is weak and prone to rupture, this dissection plane must be followed with particular care to preserve the media as intact as possible. However, the layer of the circular fibers was partially detached from both the adventitia and the plaque (Fig. 1D), forming a small flap, which was removed for histological analysis in 10 patients.

\section{Histological examinations}

Samples of plaque were removed en-bloc from all patients. A tiny oval sample of the whole wall was excised from 10 patients. This sample was approximately $2 \mathrm{~mm}$ long and $1 \mathrm{~mm}$ deep, and included the thickness of the whole wall and part of the plaque. The plaque sample was fixed in $10 \%$ buffered formalin for several days, and cut into 5-mm slices, perpendicular to the longitudinal axis. 
These tissue slices were embedded in paraffin, cut into 2- $\mu \mathrm{m}$ sections, and mounted on slides. After deparaffinization, Elastica-Masson staining was performed on each section. The most representative slice around the middle of the plaque was investigated to determine whether any media was attached to the plaque. The amount of media on the surface of the plaque was expressed as a percentage: the length of the circumference covered by the media divided by the total length of the circumference of the section. The flaps of the circular fibers and the whole wall samples were similarly stained and investigated.

\section{Results}

\section{Surgical findings}

Despite meticulous dissection of the surface of the plaque, as well as the arterial wall, the plaque was still covered with circular fibers (Fig. 2A), indicating that the dissection plane had divided the media
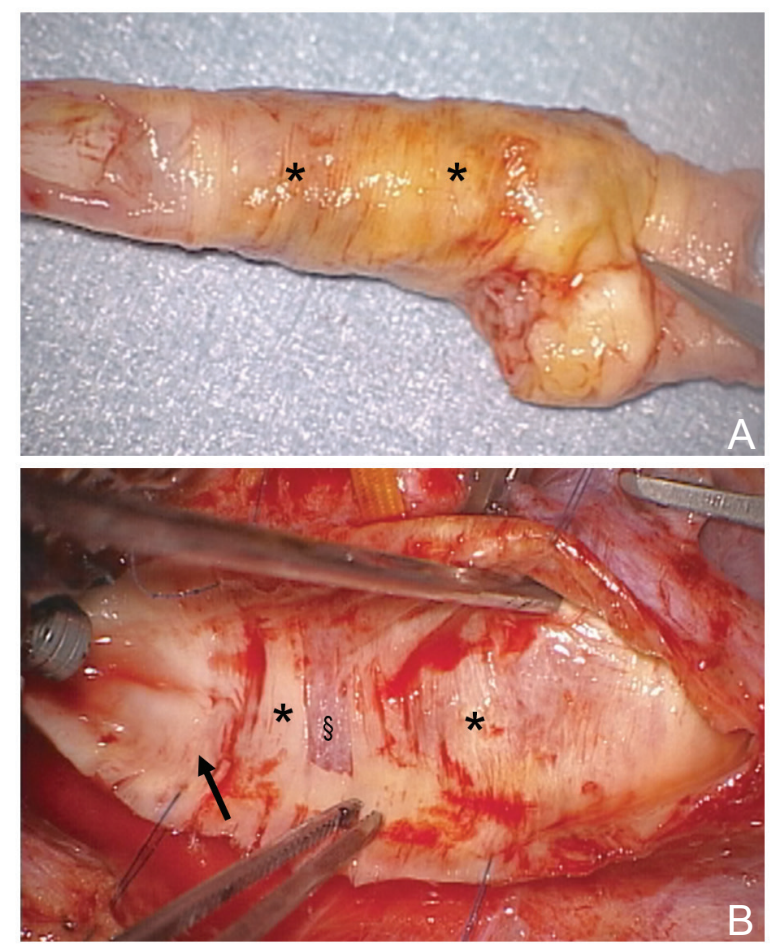

Fig. 2 Intraoperative photographs of removed plaque (A) and arterial wall after atheromectomy (B) from a different case to that presented in Fig. 1. The media (asterisks) was seen as circular fibers on both the arterial wall and the plaque. Partial exposure of the adventitia occurred where a flap of the media was removed (lower, §). Some of the media on the arterial wall was yellowish, indicating residual atheromatous components. The end of the atheromectomy transitioned smoothly to the almost normal intima of the distal internal carotid artery (arrow). into two layers. Incidental removal of a piece of the media resulted in exposure of the adventitia (Fig. 2B). Residual atheromatous components attached to the media, which appeared yellowish, often remained on the arterial wall (Figs. 1E, 2B). The transition was smooth from the end of the atheromectomy to the almost normal intima of the distal internal carotid artery (Figs. 1E, 2A). Figure 1F represents a schematic drawing of the present technique.

\section{Histological findings}

The small flap of circular fibers obtained from 10 patients demonstrated typical smooth muscle components, confirming that these formed the media (Figs. 1D, 3). A representative histological sample of the removed plaque is shown in Fig. 4. The media was observed grossly during surgery as circular fibers (Figs. 1, 2); these fibers were more clearly demonstrated by microscopic investigation (Fig. 4). More than $80 \%$ of the total circumference of the plaque section was covered by the media in 16 of the 22 patients $(73 \%)$ (Table 1 ). The tiny whole wall sample was obtained from 10 patients (Fig. 5). The media was characterized by two layers: the outer layer was almost intact, and the inner layer was more or less affected by atheromatous components, such as macrophage foam cells, in 8 of these 10 patients. The atheromatous component affected the whole thickness of the media and reached the adventitia in one patient (Table 1).

\section{Clinical consequences}

No morbidity or mortality occurred before discharge. One small ipsilateral infarction (4.5\%, including any spotty high intensity areas on the diffusion weighted

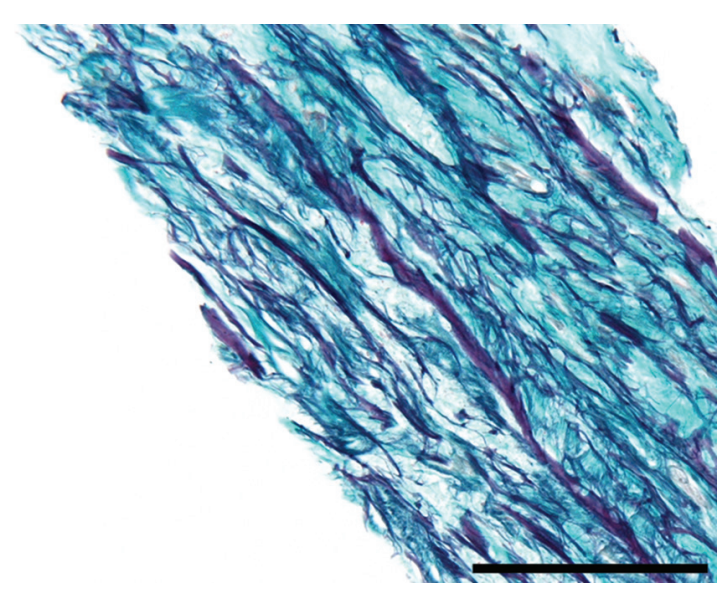

Fig. 3 Photomicrograph of the flap demonstrated in Fig. 1D (asterisks) showing typical smooth muscle component rich with elastic fibers. Elastica-Masson, original magnification $\times 400$. Scale bar $=20 \mu \mathrm{m}$. 


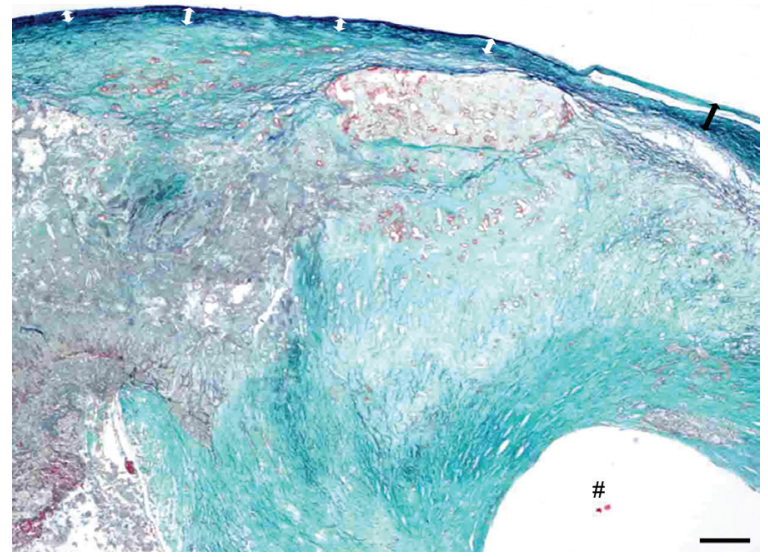

Fig. 4 Photomicrograph of the section near the middle of the removed plaque showing a thin layer of media overlying the plaque (double-headed arrows). \#: lumen. Elastica-Masson, original magnification $\times 40$. Scale bar $=20 \mu \mathrm{m}$.

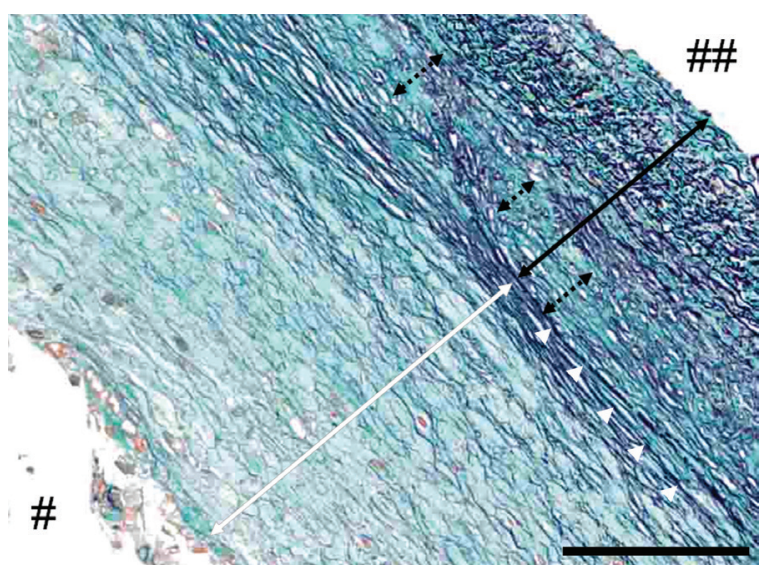

Fig. 5 Photomicrograph of the whole wall sample showing the plaque (white double-headed arrow) and the media (black double-headed arrow); \#: lumen. The adventitia has been detached from its primary position (\#\#). Residual internal elastic membrane appears to be present (white arrowheads). Part of the media is infiltrated by atheromatous components (dotted black double-headed arrows). Elastica-Masson, original magnification $\times 100$. Scale bar $=20 \mu \mathrm{m}$.

images), and no restenosis of greater than $50 \%$ were detected during the mean follow-up period of 7 years (range 4.9-7.4 years) in the 22 prospectively observed cases. Two short-term complications, transient hoarseness and transient mild hemiparesis with aphasia, were observed. The hoarseness disappeared 6 months after the operation. The hemiparesis and aphasia were thought to be due to acute occlusion of the left common carotid artery by thrombus originated from the cut edge of the plaque on the external carotid artery. The patient underwent reoperation, and the common carotid artery thrombus and the plaque on the external carotid artery were totally removed. The ischemic duration was estimated at 150-180 minutes. Although a small left frontal infarction was detected, the hemiparesis disappeared one day after the operation.

\section{Discussion}

The present study showed that the easiest dissection plane for CEA was between the media and the adventitia, implying that this plane could be widely used in CEA, in contrast to the more usual dissection plane between the intima and the media. However, this study found that dissecting this plane left almost no media on the arterial wall, as most of the media remained on the removed plaque. Our findings reflect those of several previous reports. Investigation of 147 plaques obtained at CEA found that the media was included as the outer border of the endarterectomy specimen, and suggested that a more correct term for the operative procedure might be "endomediaectomy" rather than "endarterectomy,"11) which indicates that the easiest dissection plane might extend between the media and the adventitia. Moore $^{5)}$ also emphasized the relevant issues in his textbook as follows: "Generally speaking, the easiest endarterectomy plane to achieve is that between the media and adventitia along the line of the external elastic lamina. Although some surgeons advocate this dissection plane as the best, in that it removes the circular medial fibers ..."

The present study also showed that even with careful dissection, the most of the surface of the plaque was covered by the media (Table 1), implying that the commonly recommended dissection plane between the intima and the media may not be the optimum technique if preservation of the media is intended. It is well known that the media may be affected together with the internal elastic lamina, and the border between the media and the plaque may be obscure in advanced plaque. ${ }^{7)}$ Therefore, the best dissection plane may be located within the media, between the luminal part of the media which is highly invaded by the plaque, and the outer part of the media which is less severely invaded. This dissection plane preserves the maximum media but was tighter than other dissection planes, so continuous effort to follow the plane was necessary. This plane also needed forceful opening at the beginning of the dissection, and following this plane also required careful dissection.

Maximum preservation of the media in cases with advanced plaques resulted in some remnant yellow 
atheromatous components within the preserved media. Consequently, this technique may possibly be associated with increased rates of ipsilateral stroke or restenosis. However, only 1 of our 22 patients $(4.5 \%)$ suffered a small ipsilateral infarction, and no patients had ipsilateral restenosis greater than $50 \%$ during the mean follow-up period of 7 years. Moreover, in our series of 202 consecutive patients treated by CEA using the same technique between April 1998 and March 2008, including the present 22 patients, 11 patients $(5.4 \%)$ suffered ipsilateral restenosis greater than $50 \%$ and/or any ipsilateral infarctions including spotty high intensity area of the diffusion weighted imaging during the mean long-term follow-up period of 5.7 years (range 35 days to 11.6 years, unpublished data). Our long-term follow-up examinations demonstrated no increase in complications compared to historical controls documenting a $9-10.8 \%$ rate of ipsilateral stroke during the long-term follow-up period of 3-10 years. ${ }^{14,15)}$

The advantages of our technique are as follows: First, as a result of preserving the media, the distal end of the endarterectomy smoothly transits to the intima of the internal carotid artery (Figs. 1F, 6). This is an important requirement of $\mathrm{CEA}^{5}$ to avoid postoperative ischemic complication or occlusion of the carotid artery. Tacking sutures are not necessary if the media is preserved. Second, the firm arterial wall enables easy hemostasis during arterial closure. Third, it may be important for surgeons under training, because they often face questions; which plane should be dissected and whether small amount of plaque invading into the media or, sometimes, adventitia should be removed or not. The present study clarified the relationship between the media and dissection plane and no harmful effect of small remnant of the plaque. The present technique may be useful especially if the plaque invaded adventitia.

The limitations of our study are that the usual technique to remove most of the media is not associated with surgical complications, and the clinical impact of preserving the media is obscure. Both techniques cannot be compared in terms of direct clinical superiority at present. Nevertheless, the present surgical technique does increase our knowledge of the theoretical background and, therefore, potentially contributes to the advancement of CEA.

\section{Conclusion}

Atheromatous components usually invade the luminal surface of the media, so the optimum dissection plane for CEA may be within the media, dividing it into two layers. This technique results in smooth transition to the normal intima at the distal end of
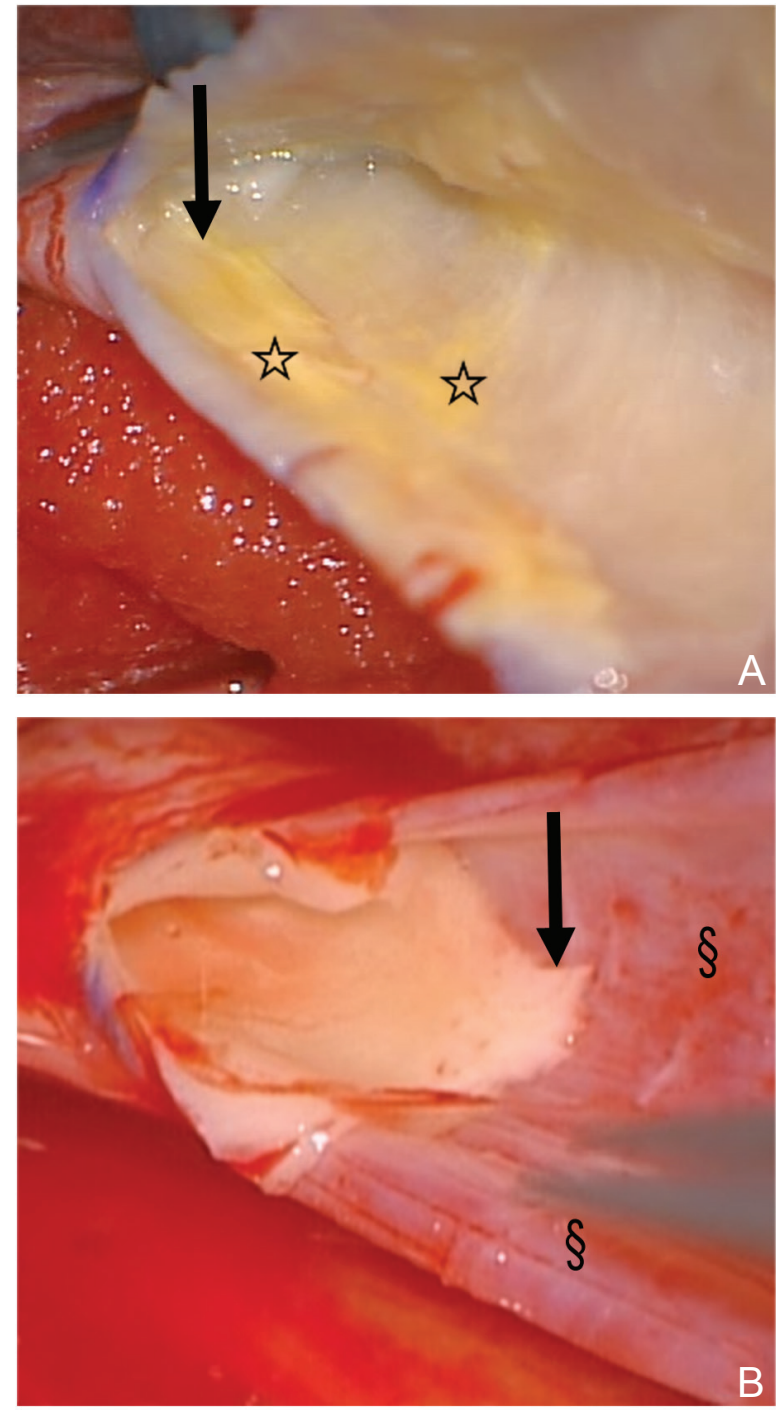

Fig. 6 Intraoperative photographs of the distal end of the endarterectomy with (A) and without (B) the present technique. A: The preserved media with some residual atheromatous components (stars) smoothly transited to the intima of the internal carotid artery (arrow). B: Most of the media was removed and the adventitia appeared as the red wall (§). The distal end of the endarterectomy did not smoothly transit to the intima of the internal carotid artery (arrow).

the internal carotid artery and, despite some atheromatous components remaining with the preserved media, no increases in surgical complications or restenosis.

\section{Conflicts of Interest Disclosure}

The authors report no conflict of interest concerning the materials or methods used in this study or the findings specified in this article. 


\section{References}

1) Sacco RL, Adams R, Albers G, Alberts MJ, Benavente O, Furie K, Goldstein LB, Gorelick P, Halperin J, Harbaugh R, Johnston SC, Katzan I, Kelly-Hayes M, Kenton EJ, Marks M, Schwamm LH, Tomsick T; American Heart Association; American Stroke Association Council on Stroke; Council on Cardiovascular Radiology and Intervention; American Academy of Neurology: Guidelines for prevention of stroke in patients with ischemic stroke or transient ischemic attack: a statement for healthcare professionals from the American Heart Association/American Stroke Association Council on Stroke: co-sponsored by the Council on Cardiovascular Radiology and Intervention: the American Academy of Neurology affirms the value of this guideline. Stroke 37: 577-617, 2006

2) Bonati LH, Ederle J, McCabe DJ, Dobson J, Featherstone RL, Gaines PA, Beard JD, Venables GS, Markus HS, Clifton A, Sandercock P, Brown MM; CAVATAS Investigators: Long-term risk of carotid restenosis in patients randomly assigned to endovascular treatment or endarterectomy in the Carotid and Vertebral Artery Transluminal Angioplasty Study (CAVATAS): long-term follow-up of a randomised trial. Lancet Neurol 8: 908-917, 2009

3) Brott TG, Hobson RW, Howard G, Roubin GS, Clark WM, Brooks W, Mackey A, Hill MD, Leimgruber PP, Sheffet AJ, Howard VJ, Moore WS, Voeks JH, Hopkins LN, Cutlip DE, Cohen DJ, Popma JJ, Ferguson RD, Cohen SN, Blackshear JL, Silver FL, Mohr JP, Lal BK, Meschia JF; CREST Investigators: Stenting versus endarterectomy for treatment of carotid-artery stenosis. N Engl J Med 363: 11-23, 2010

4) Yadav JS, Wholey MH, Kuntz RE, Fayad P, Katzen BT, Mishkel GJ, Bajwa TK, Whitlow P, Strickman NE, Jaff MR, Popma JJ, Snead DB, Cutlip DE, Firth BG, Ouriel K; Stenting and Angioplasty with Protection in Patients at High Risk for Endarterectomy Investigators: Protected carotid-artery stenting versus endarterectomy in high-risk patients. $N$ Engl J Med 351: 1493-1501, 2004

5) Moore WS: Technique of carotid endarterectomy, in Moore WS (ed): Surgery for Cerebrovascular Disease, 2nd edition. Philadelphia, WB Saunders, 1996, pp 368-377

6) Schoen FJ, Cotran RS: The blood vessels, in Schmitt W (ed): Robbins Basic Pathology, 7th edition. Philadelphia, Saunders, 2003, pp 325-360

7) Stary HC, Chandler AB, Dinsmore RE, Fuster V, Glagov S, Insull W, Rosenfeld ME, Schwartz CJ, Wagner WD, Wissler RW: A definition of advanced types of atherosclerotic lesions and a histological classification of atherosclerosis. A report from the Committee on Vascular Lesions of the Council on Arteriosclerosis, American Heart Association. Arterioscler Thromb Vasc Biol 15: 1512-1531, 1995

8) Bock RW, Lusby RJ: Lesions, dynamics, and pathogenic mechanisms responsible for ischemic events in the brain, in Moore WS (ed): Surgery for Cerebrovascular Disease, 2nd edition. Philadelphia, WB Saunders, 1996, pp 48-71

9) Crowell RM, Ogilvy CS, Ojemann RG, Heros RC: Carotid endarterectomy. In Ojemann RG, Ogilvy CS, Crowell RM, Heros RC (eds): Surgical Management of Neurovascular Disease, 3rd edition. Baltimore, Williams \& Wilkins, 1995, pp 42-54

10) Mayberg RM: Extracranial occlusive disease of the carotid artery. In Youmans JR (ed): Neurological Surgery, 4th edition. Philadelphia, WB Saunders, 1996, Vol 2, pp 1172-1173

11) Roberts WC, Laborde NJ, Pearl GJ: Frequency and extent of media in the internal carotid artery in "endarterectomy" specimens. Am J Cardiol 99: 990-992, 2007

12) Adams HP, del Zoppo G, Alberts MJ, Bhatt DL, Brass L, Furlan A, Grubb RL, Higashida RT, Jauch EC, Kidwell C, Lyden PD, Morgenstern LB, Qureshi AI, Rosenwasser RH, Scott PA, Wijdicks EF; American Heart Association; American Stroke Association Stroke Council; Clinical Cardiology Council; Cardiovascular Radiology and Intervention Council; Atherosclerotic Peripheral Vascular Disease and Quality of Care Outcomes in Research Interdisciplinary Working Groups: Guidelines for the early management of adults with ischemic stroke: a guideline from the American Heart Association/American Stroke Association Stroke Council, Clinical Cardiology Council, Cardiovascular Radiology and Intervention Council, and the Atherosclerotic Peripheral Vascular Disease and Quality of Care Outcomes in Research Interdisciplinary Working Groups: the American Academy of Neurology affirms the value of this guideline as an educational tool for neurologists. Stroke 38: 1655-1711, 2007

13) Shinohara Y, Yamaguchi T: Outline of the Japanese Guidelines for the Management of Stroke 2004 and subsequent revision. Int J Stroke 3: 55-62, 2008

14) Halliday A, Harrison M, Hayter E, Kong X, Mansfield A, Marro J, Pan H, Peto R, Potter J, Rahimi K, Rau A, Robertson S, Streifler J, Thomas D; Asymptomatic Carotid Surgery Trial (ACST) Collaborative Group: 10-year stroke prevention after successful carotid endarterectomy for asymptomatic stenosis (ACST-1): a multicentre randomised trial. Lancet 376: 1074-1084, 2010

15) North American Symptomatic Carotid Endarterectomy Trial Collaborators: Beneficial effect of carotid endarterectomy in symptomatic patients with highgrade carotid stenosis. N Engl J Med 325: 445-453, 1991

Address reprint requests to: Kuniyasu Niizuma, MD, PhD, Department of Neurosurgery, Tohoku University Graduate School of Medicine, 1-1 Seiryo-machi, Aoba-ku, Sendai, Miyagi 980-8574, Japan. e-mail: niizuma@nsg.med.tohoku.ac.jp

Neurol Med Chir (Tokyo) 54, October, 2014 